\title{
8
}

\section{Equal Respect for Rational Agency}

\author{
Michael Cholbi
}

The Kantian project in moral philosophy invariably confronts naturalistic headwinds. But these headwinds have become stronger in recent years, thanks to a growing body of evidence indicating that human choice and attitude formation is subject to an array of biases that render much of what we think and do irrational-or at least, less than ideally rational. A full catalog of these biases is impossible here, but among the better established are that we are time-biased, fixating on immediate outcomes of our choices while discounting future gains or losses; ${ }^{1}$ that we assign greater significance to losses in well-being than we do to equivalent gains to well-being; ${ }^{2}$ that our choices are heavily influenced by the order in which alternatives are presented to $\mathrm{us}^{3}$ or by how those alternatives are described (so-called 'framing effects'); ${ }^{4}$ that our choices are often swayed by striking and memorable examples rather than by the totality of evidence available to us ("availability heuristics"); ${ }^{5}$ and we tend to choose quickly and lazily, not bothering (for example) to investigate alternatives to options that others have set as defaults for us. ${ }^{6}$ In the economic idiom used by Cass Sunstein, these biases generate

1 T. O’Donoghue, and M. Rabin, “Doing It Now or Later," American Economic Review 89 (1999): 103-24.

2 Daniel Kahneman and Amos Tversky, "Choices, Values, and Frames," American Psychologist 39 (1984): 341-50.

3 William D. Perreault, "Controlling Order-Effect Bias," Public Opinion Quarterly 39 (1975): 544-51.

4 Amos Tversky and Daniel Kahneman, "The Framing of Decisions and the Psychology of Choice," Science 211 (1981): 453-8.

5 Amos Tversky and Daniel Kahneman, "Availability: A Heuristic for Judging Frequency and Probability," Cognitive Psychology 5 (1973): 207-32.

${ }^{6}$ Richard H. Thaler and Cass Sunstein, Nudge: Improving Decisions about Health, Wealth, and Happiness (New Haven: Yale University Press, 2008). 
"behavioral market failures," wherein our desires, preferences, or wellbeing are not as fully realized as they would be absent such biases. ${ }^{7}$

For Kantians, such findings may seem troubling. For the heart of the Kantian moral outlook, in the eyes of many its contemporary defenders, is that we owe respect to rational agents on more or less equal terms. In the terms made famous by Kant's Formula of Humanity, we owe equal respect to persons by dint of their 'humanity' or rational agency, and more specifically because persons possess the practically rational capacities to set ends for themselves and to select adequate means to those ends. ${ }^{8}$ The various choice biases identified in the psychological literature suggest these capacities are much wobblier than we tend to assume, particularly with respect to prudential or instrumental rationality. Again, just to take one example: That we are subject to framing effects wherein our choices often vary in response to how risky options are described (we are more likely to reject an option described as having a $20 \%$ chance of failure than to reject that same option when described as having an $80 \%$ chance of success, for instance) suggests that the mechanisms by which we choose the means to our ends fail to track features relevant to the rationality of choice.

Admittedly, that we often choose irrationally does not entail that we are not capable of rational choice or that we are not, in some generic sense, rational agents. Nevertheless, if the picture of human psychology suggested by this body of research into choice bias is correct, then the Kantian claim that rational agency is entitled to respect appears to rest on a dubious picture of human nature. Why, critics might ask, ought we respect human agents for something that they are evidently not, i.e., rational choosers? At a more theoretical level, if rational choice seems to be the exception rather than the rule in human psychology, this calls into question the common strategy of assuming that we are rational choosers and then proceeding to accommodate deviations from norms

${ }^{7}$ Why Nudge?: The Politics of Libertarian Paternalism (New Haven: Yale University Press, 2014).

${ }^{8}$ See Kant, Metaphysics of Morals, Berlin Akademie edition (1900-), 6: 392, and Christine Korsgaard, “Kant's Formula of Humanity," Kant-Studien 77 (1986): 183-202. 'Humanity' arguably also includes the more general rational capacity to act on the basis of, and not merely in conformity with, principles or 'laws'. 
of rational choice as 'non-ideal'. Kantianism instead emerges as a suspect version of an ideal theory. For if human agents are systematically irrational, then the thesis that we owe respect to human beings insofar as they are rational agents-or even just insofar as they are practically rational agents-might appear as credible as the theses that we are owed respect because we can run a four-minute mile or do long division in our heads. And if human agents vary widely in their ability to form attitudes on rational grounds, then a fortiori, the Kantian commitment to equal respect is imperiled as well.

Kantians can respond to these findings of systemic bias in three ways. First, they might attempt to discredit the relevant scientific evidence. Second, they might grant these scientific findings accurately describe human psychology but deny that they are evidence of irrational biases. Third, they may concede that humans are subject to these irrational biases but deny that this necessitates jettisoning the Kantian project altogether. They might, in other words, develop a theory that accommodates these irrational biases, articulating how equal respect for rational agency can still be a candidate for a-or even, the-fundamental moral norm even if human agents are biased in these ways.

This chapter sets aside the first ${ }^{9}$ and second responses so as to develop what I hope will be a compelling version of the third. Section 1 clarifies the nature of respect and what would need to be true of rational agents in order for them to be owed equal respect. Sections 2 through 4 consider three different alternatives for what the object of equal respect might be. According to the first alternative, respect is owed when agents satisfactorily exercise their rational agency. According to the second alternative, respect is owed because agents possess a minimal capacity for such agency. I argue in favor of a third alternative wherein the object of rational respect is our aspiration to govern our lives rationally. This third alternative encompasses the second inasmuch as individuals must have some minimal capacity for rational agency in order to be owed respect. But this capacity is not what justifies respect for rational agency.

\footnotetext{
9 Though for a suggestive critique of the studies that purport to demonstrate such biases, see Stephen Poole, "Not so foolish," Aeon, 22 Sept. 2014 (https://aeon.co/essays/we-are-morerational-than-those-who-nudge-us, accessed 16 Apr. 2018)
} 
Rather, our aspiration toward rational self-governance grounds equal respect. This aspiration functions as a regulative ideal, both presupposed and aspired toward in our deliberations about our choices and attitudes. Aspirational constitutivism best answers to the moral demands of equal respect for rational agency while acknowledging our apparently natural tendencies to irrational attitude formation and choice. In my conclusion, I outline how standard Kantian approaches to addressing how the moral norm of equal respect for rational agency should account for imperfect rational agency have rested on a wrongheaded methodological assumption, namely, that such imperfections represent deviations from ideal circumstances, such that they are to be addressed via a non-ideal theory modeled on an ideal theory that assumes no such deviations. I propose, in contrast, that a defense of equal respect for rational agency should be non-ideal at the ground level, such that equal respect is owed to imperfectly rational agents because of, rather than despite, such imperfections.

\section{Respect and Equality}

Central to any defense of equal respect for rational agency as a fundamental moral norm is the specification of exactly what notion of 'rational agency' can best play the role of what Jeremy Waldron has called the "host property" that serves as the shared ground of basic moral status. ${ }^{10}$ The notions of respect and equality presumably constrain what sorts of property could play this role, so some preliminary remarks about respect and equality are necessary before we consider candidates for this property.

In order for respect to be owed equally to persons, respect must be grounded in, or directed at, some property they have qua persons. The respect in question therefore cannot be a form of esteem, or what Darwall famously called "appraisal respect," the sort of respect that rests on a positive appraisal of someone due to contingent but admirable or praiseworthy attributes she has, such as a pleasant singing voice or

\footnotetext{
${ }^{10}$ One Another's Equals (Cambridge, MA: Belknap/Harvard University Press, 2017), p. 86.
} 
having three times been named salesperson of the year. Equal respect can only take the form of what Darwall called "recognition respect," which manifests as a disposition to assign weight in one's deliberation to some feature of a person qua person that in turn justifies guiding one's conduct toward the person in light of that fact. ${ }^{11}$ Recognition respect is owed to those things with an inherently high or distinctive status, a status "left over when you take merit away or set it aside." ${ }^{12}$ Recognition respect is thus owed and can be rightfully asserted or claimed, but is neither earned nor deserved. Note that while variations in appraisal respect are calibrated to variations in individuals' worthiness to be esteemed, recognition respect is not appropriately calibrated to any such variations because it is directed toward someone due to her inherent status. So long as a being has such a status, she is owed recognition on the same terms as anyone else with whom she shares that status. Hence, recognition respect is a candidate for the sort of respect grounding a norm of equal respect, whereas appraisal respect is not.

These remarks illustrate how the notion of equality constrains the property that might ground equal respect for rational agency. But how does respect itself constrain that property? Respect is one of the many evaluative attitudes we might take toward something or someone. What are its distinguishing features? To start, Harry Frankfurt highlights how the antithesis of respect, disrespect, feels like a denial of a person's "nature." To be disrespected is for others to treat a person as though "the person ... is not what he actually is." ${ }^{13}$ These remarks underscore how respecting something involves a recognition of, and a proper response to, that thing's nature. Consider the etymology of 'respect,' literally, 'to look again' or to reconsider. "Respect," Robin Dillon notes, "is a particular mode of apprehending the object: the person who respects something pays attention to it and perceives it differently from someone who does not and responds to it in light of that perception." ${ }^{14}$ When we disrespect a person, we fail to attend to whatever property is most central to them

11 “Two Kinds of Respect," Ethics, 88 (1977): 36-49.

12 Waldron, One Another's Equals, p. 2.

13 On Inequality (Princeton UP, 2015), pp. 86-7.

14 "Respect," Stanford Encyclopedia of Philosophy, section 1.1 (https://plato.stanford.edu/ entries/respect/, accessed 24 Mar 2018). 
or to acknowledge what they most fundamentally are. In many such failures, our conduct toward them was instead oriented toward some other property, more incidental to their personhood, that likely had evaluative significance for us: that the individual is attractive or has talents or resources useful in helping us secure our ends. As Rawls (echoing Kant) has it, respect should directly determine "our will without reference to what is wanted by our inclinations." ${ }^{15}$

Equal respect does not require that persons be precisely equal with regard to those aspects of personhood that ground respect. Many persons can be tall without being the same height, or musically talented without all being able to play the same instruments. Likewise, whatever property grounds equal respect need not be one that human choosers have to the same degree or in precisely the same form. Equal respect may well rest on a "range property," a property realized, in typical human choosers, to a sufficient degree so as to exceed some threshold but that choosers individually exceed to varying degrees. ${ }^{16}$ Waldron offers a comparison to the property being in Scotland. Aberdeen and Glasgow both have this property, though Aberdeen is farther from Scotland's "threshold" with England than is Glasgow.

Recognition respect, in my estimation, is just the kind of property that is likely to be rooted in a range property. For as Ian Carter has observed, this kind of respect requires prescinding from treating others on the basis of judgments, however well grounded, of precisely how fully realized or capably exercised their powers of rational agency are. Except for special contexts where our goal is to evaluate rational capacity-a psychiatrist determining if an accused person is fit to stand trial, say-respect requires us to treat others as "opaque," not 'looking inside' them in order to decide how they ought to be treated. ${ }^{17}$ In thereby taking another as 'given', we establish and honor the sort of distance between agents that, as Kant observed, is characteristic of respect. ${ }^{18}$ In

\footnotetext{
15 John Rawls, Lectures on the History of Moral Philosophy, Barbara Herman (ed.) (Cambridge, Mass: Harvard University Press, 2000), p. 153.

${ }^{16}$ John Rawls, A Theory of Justice (Cambridge, Mass.: Belknap/Harvard University Press, 1971), p. 444.

17 "Respect and the Basis of Equality," Ethics 122 (2011), pp. 551-3.

${ }_{18}$ MM 6:449. For further elaboration of Kant's claim, see my Understanding Kant's Ethics (Cambridge: Cambridge University Press, 2016), pp. 65-6.
} 
this way, we take into account that respect is owed to anyone whose rational agency falls within the bounds set by the relevant range property rather than tailoring our treatment of rational agents based on the degree to which they exceed those bounds.

Respect thus invites us to adopt of attitudes of deference toward whatever is entitled to respect. Those entities meriting respect should be left essentially in the state they are, to enjoy a kind of intactness or integrity. This applies not only to persons, but other entities that might be worthy of respect, such as extraordinary elements of the natural world, noteworthy artworks, or other human achievements. We respect Iguazu Falls, or the Magna Carta, or the Apollo XI lunar lander principally by leaving them be. Those things meriting respect therefore ought not, without extremely compelling reason, be modified to fit our purposes. Respect thus does not ask us to change its object's nature. Rather, it asks us to step back and revere that object for being essentially what it is.

These remarks about the nature of equality and respect suggest desiderata about the host property that might make sense of equal respect for rational agency as a fundamental moral norm. Let us now consider three candidates for such a host property.

\section{Exercising Rational Agency}

One possible gloss on respect for rational agency is that it should be understood as directed toward successful exercises of rational agency. On this picture, respect for rational agency requires that we defer to all and only those choices of others that are in fact practically rational. I will not advance a position here as to exactly what criteria an agent's choices must meet in order to be practically rational. But on this picture of respect for rational agency, choices that do not meet those criteria need not be respected, which (as we saw in the previous section) means that they ought not be deferred to or viewed as authoritative.

The obvious advantage of viewing exercising rational agency as the grounds for equal respect is that it provides a straightforward and credible rebuttal to the earlier worries about our tendencies toward irrational choice. If so many of our choices are practically irrational, then 
let us not respect those choices but instead reserve respect for that subset of choices (however minute) that satisfy the standards for practical rationality.

Exercising rational agency has little to recommend it, though, as a candidate for the property that might ground equal respect for rational agency. For one, it is likely to have strongly inegalitarian implications. It may be, as Bence Nanay ${ }^{19}$ has it, that we are all stupid. But it would be surprising if we were even roughly equally stupid. To ground respect in exercising rational agency is thus likely to accord such widely varying amounts of respect to agents so as not to recommend anything resembling equal respect for them.

In addition, for equal respect to be directed at exercises of rational agency falls short of what seems to matter about respect. The yearning to be respected is, as the previous section outlined, a yearning that something essential about us be deferred to. Respecting our choices matters to us because they reflect something about us as choosers and valuers. Not respecting our choices is evidence that we are not respected. Yet to restrict respect to our rational choices rests on an unduly narrow conception of what we are. For us, rational agency is a causal, but not a mechanical, power: Our deliberation, habits, etc. shape our choices, and our choices in turn shape the intentions, desires, and other states that give rise to action. But at every stage of the exercise of rational agency, we are, as the choice bias literature reminds us, fallible creatures. This fallibility reflects the fact that our rational powers are normative as well as causal, susceptible to error rather than operating infallibly in accordance with fixed laws. Respect for us as we are must therefore reflect this fallibility. So when our choices fail to satisfy standards for rational choice, this ought not be seen as a kind of malfunction akin to the failure of some non-agential physical system, as when a knife fails to cut or a computer fails to boot up. Failures of rational agency are still manifestations of rational agency understood as a normative power. To make an irrational choice is to manifest our natures while simultaneously failing

\footnotetext{
19 "Stupidity is Part of Human Nature: Why We're Better Off Giving Up the Myth of Perfect Rationality," IAI News, 25 April 2018 (https://iainews.iai.tv/articles/why-stupidity-is-part-ofhuman-nature-auid-1072? access=All\%3Futmsource\%3DReddit\#_prclt=bjBFXCqG, accessed 27 April 2018).
} 
to live up to the demands established by those natures. Thus, if an individual's rational choice to do $\mathrm{A}$ is to be respected but her less than rational choice to do $\mathrm{B}$ is not, then that individual is not respected for the sort of rational agent she is. To say that the norm of equal respect requires 'respecting' only our rational choices is not to heed or defer to our rational agency on the basis of the kind of entity it is (i.e., an imperfect normative power). Respecting only rational choices is thus to hold persons to a standard of respect inappropriate to the nature of the entities they are. To the extent that satisfactory exercises of rational agency necessitate respect at all, they necessitate appraisal respect, not the recognition respect associated with respect for persons.

In sum, the very considerations that enable this first alternative to rebut the worries about irrational bias hamper its ability to undergird a norm of equal respect for rational agents. For grounding equal respect in exercises of rational agency rebuts those worries only at the cost of jettisoning both equality and respect.

\section{Rational Capacity}

A more orthodox Kantian gloss on respect for rational agency understands it in terms of a capacity or set of powers. On this picture, so long as a choice is made by an individual minimally possessed of the powers of rational agency, then their choices are to be respected, even if those choices are substantively irrational as a matter of fact. Rational choices merit respect on this model, but so too do irrational choices if, counterfactually, the individual could have exercised her rational capacities to choose rationally.

Grounding equal respect in rational capacities has a number of dialectical advantages. It incorporates a genuine form of respect for rational agents, inasmuch as it requires others to defer to them even in instances of irrational choice and so recognizes their nature as beings possessed of normative (rather than purely causal) powers of choice. On the condition that the threshold for possessing the relevant rational capacities is not set unduly high, this alternative also avoids the inegalitarian implications that beset the previous alternative. Finally, grounding 
equal respect in rational capacities holds promise in rebutting worries about systemic rational bias and thereby salvaging the Kantian moral project. For this alternative does not require that our choices be rational in order to be owed respect; rather, even choices influenced by all-too-human biases are owed respect if the agent had the capacity to choose differently.

While a capacity for minimally rational practical agency is necessary for equal respect, it is not, in my estimation, sufficient. To see why, imagine an intelligent robot-like machine, akin to Clarke and Kubrick's HAL, equipped with powers of rational choice-at a minimum, the capacity for instrumental reasoning against some pre-programmed background of ends, say, self-preservation. It possesses the 'cognitive' firepower to identify sufficient means to some set of ends, and it is programmed to be 'committed' to its ends or goals. Such a machine could weigh ends of immediate urgency against those of long-term significance; could ascertain causal relations between particular courses of its action and its ends; etc. Assuming that its programming is adequately designed, such a machine would be highly efficient in its pursuit of its ends.

But would such an entity be entitled to moral respect from us, the kind of deference Kantians have in mind? Our question is not 'firstpersonal,' i.e., whether such an entity could or would demand respect for others. Rather, our question is whether an entity with perfect instrumental rationality should be recognized as worthy of recognition respect. One reason for doubt is that this machine lacks one aspect of Kantian humanity, to wit, the capacity to set ends. While correct, this is not our strongest reason to withhold recognition respect from it. Rather, the instrumentally rational machine has no reason to care about whether its choices are rational. Our machine is not invested in its sole end of self-preservation in the way that we imperfectly rational agents are invested in our ends. Its choices make a difference to whether the machine survives, but whether it survives may not make a difference to the machine. If the machine can be said to have a 'perspective', it does not matter from its perspective whether it (or its choices) are respected.

We, on the other hand, wish to be respected as rational choosers. How come? For us, practical rationality is both a boon and a bane, a set of 
normative powers that enables us to choose and to act, but a set of powers that is fallible in that regard as well. To choose rationally is therefore an achievement for $\mathrm{us}^{20}$ in a way that it is not for a perfectly rational machine. Because rational choice is in varying degrees difficult for us, rational self-governance requires effortful exercises over time of our rational wills. To not respect us as rational agents is to overlook how our very fallibility as rational choosers provides the background condition for us caring about our rational agency. Being imperfect, our rational agency matters to us because it establishes a problematic for us, as well as containing the seeds of the solution of that problematic. Our aspiration to choose rationally occurs against an awareness that our agency, being a normative power, sometimes fail. This awareness drives our aspiration to rational choice, as well as inducing anxiety about whether our choices are rational. A perfectly rational machine, in contrast, suffers no anxiety about whether its choices (or its ends) are rational or not. They do not face choices that they view as puzzling, momentous, or pivotal. Practical rationality is not worrying for such a machine in the way it can be and often is for us; we aspire to be rational because our limitations, including our susceptibility to various forms of irrational bias in choice, make rational choosing an achievement for us. ${ }^{21}$ Rational choice thus solves a difficulty posed to us by our infallible natures, whereas in the robot's case, its choices, while rational, do not address a challenge rooted in its nature.

Respecting a rational agent requires that they be an agent with rational capacities. Yet respect-worthy moral personhood thus requires more than the cognitive machinery of rational choice. Moral personhood also necessarily involves a desiderative orientation, a disposition not only to rationally deliberate but to deliberate in ways evincing concern

20 Gwen Bradford, Achievement (Oxford: Oxford University Press, 2015).

${ }^{21}$ Does the fact that respect for rational agents rests on their being imperfectly rationalagents for whom rational choice is fallible and hence problematic-entail that that we ought not respect a perfectly rational God? This contention assumes that human respect for the deity is a form of recognition-respect, rooted in God's nature. This appears plausible, since God's nature (as it has been understood in the monotheistic faiths) as perfectly just, all-knowing, etc. is respect-worthy. However, I harbor doubts that respect for God is genuinely a form of recognition-respect. For what we seem to respect about God is God's perfect rationality, and indeed, as the persistence of the theological problem of evil might suggest, our respect or esteem for God appears to pivot on our appraisal of God as perfectly rational, etc. 
for the rationality of one's choices. And only agents for whom rational agency is a tool-and the exercise of rational agency a task for which success is possible but not inevitable-can have such a desiderative orientation. Hence, respect-worthy rational agents are not simply agents who can engage in rational choice. They are also agents for whom it matters to them, however inchoately, that they engage in rational choice. Whatever its powers of rational choice may consist in, in the absence of the machine being able to care about whether its choices are rational, such a machine would not be morally entitled to the sort of respect specifically owed to persons. We might appraisal respect their rational agency, esteeming or admiring its efficacy. But their rational agency is not something we need recognize as imposing moral constraints on how we engage with them.

To be worthy of respect as a rational agent, then, is not merely a metaphysical matter. One must be able to be rational to be so respected. But respect for rational agency is properly directed at agents for whom rational agency is an aspiration.

\section{Aspirational Constitutivism}

Hence, on the view of equal respect for rational agency I favor, aspirational constitutivism, individuals must have some minimal capacity for rational agency in order to be owed respect, but this capacity is not the basis for respect. Rather, the 'host property' that serves as the object of respect is the aspiration to rational self-governance. We are imperfect rational agents, beings who can and do entertain, and occasionally puzzle over, questions about what to do, be, or become. Indeed, our lives are suffused with normative questions, not only Korsgaard's normative question about the authority of morality, but a myriad of questions, some grand and others pedestrian, of practical import. It is not simply that such questions often feel unavoidable; after all, something must be done, and even deciding to 'do nothing' is a choice of sorts. Rather, we take these questions with varying degrees of seriousness and typically presuppose that they have right (or at least, better or worse) answers. In entertaining such questions, we evince our aspiration to choose rightly, 


\section{MICHAEL CHOLBI}

well, or properly - that is to say, rationally. Frankfurt captures how the aspiration resides near the core of our self-understanding:

... we are not prepared to accept ourselves just as we come. We want our thoughts, our feelings, our choices, and our behavior to make sense. We are not satisfied to think that our ideas are formed haphazardly, or that our actions are driven by transient and opaque impulses or by mindless decisions. We need to direct ourselves-or at any rate to believe that we are directing ourselves-in thoughtful conformity to stable and appropriate norms. We want to get things right. ${ }^{22}$

If aspirational constitutivism is correct, these same yearnings to "get things right" and for our "behavior to make sense" also undergirds the respect that compels others to take us seriously.

The aspiration toward rational self-governance is evident in regard to particular choices we must make. But it also arises in so far as we are called upon to make interrelated choices at various times. Circumstances can necessitate revisiting past choices or require that we choose now about what sorts of options, and hence what sorts of choices, will be available to us in the future. Past choices can be instructive about our ends, both how alternative ends sit with us and how they integrate with one another. Past choices can also be instructive about which means best serve the ends to which we are committed. For beings like ourselves, equipped with powers of memory and anticipation as well an awareness of time's elapsing, being a rational agent is thus an ongoing, kinetic undertaking. The aspiration to rationally govern one's life is hence not (or not merely) a desire to govern this or that choice rationally. It is the aspiration to govern our biographies rationally over expanses of timeat its limit, over the entirety of one's lifespan. The aspiration to govern one's life rationally thus has duration because we live temporally inflected lives.

This aspiration is closely related to what George Sher called "effectiveness." Each of us, Sher argues, is a distinct subjectivity linked to past

22 Taking Ourselves Seriously and Getting It Right (Palo Alto: Stanford University Press, 2006), p. 2. 
and future events. We thus have a "fundamental interest" in rationally organizing our lives diachronically so as to live a life that "is future oriented, active, reason-guided, and organized around an enduring though evolving set of aims"23 that shift in response to contingencies. I propose that in "assessing the reasons with which one's evolving situation provides one, forming and pursuing aims, intentions, and plans that reflect those assessments," ${ }^{24}$ we betray the implicit aspiration for rational self-governance that is the proper object of respect.

In many respects, rational agency functions as a regulative ideal for imperfectly rational agents such as ourselves. For Kant, regulative ideals (such as the unification of the sciences) establish an agenda for a given practice or inquiry. A regulative ideal animates a practice inasmuch those participants in the practice assume that the ideal is achievable through that practice without having decisive theoretical evidence of its achievability. A regulative ideal thus represents an aspiration presupposed in some practice of inquiry. Practical rationality, I hypothesize, ought be respected because success in practical choice serves as a de facto regulative ideal in the practical realm: We assume that our choices both do and ought to conform of standards of practical rationality-and upon learning that some of our choices do not, we do not relinquish this ideal but wish to better realize it. ${ }^{25}$

Before turning to the advantages of aspirational constitutivism as an account of the property that grounds the moral norm of equal respect for rational agency, let me address two immediate worries.

First, it may just seem odd that a particular attitude itself, rather than some more generic feature of rational agency, could be the property that explains why rational agency ought to be respected. But it is not so odd. Recall that respect is directed at properties that reside near the heart of the respected entity's nature. If the aspiration for rational self-governance is part of our nature, then it is hard to see why it could not be a candidate for the property that grounds respect for persons. Keep in

${ }^{23}$ Equality for Inegalitarians (Cambridge: Cambridge University Press, 2014), p. 95.

24 Equality for Inegalitarians, p. 96.

${ }^{25}$ For more on how regulative ideals can play a role in the practical realm, see my "The denial of moral dilemmas as a regulative ideal," Canadian Journal of Philosophy 46 (2016): 268-89. 
mind that the proposed object of respect is not the successful realization of this aspiration but the aspiration itself. And that aspiration survives even when we fail to realize it.

Second, is it part of our nature? No doubt the aspiration toward rational self-governance is apparent in the classic 'type A' personality. But what of the type B's, who only infrequently reflect on their choices, are more 'in the moment' and content 'to live and let live'? Can we really say that (for instance) the individual in Kant's third illustration of the Categorical Imperative, a slacker-like figure willing to let his talents rust rather than be diverted from his immediate pleasures, aspires to live a rational life?

Clearly, if human agents share this aspiration, they are not equally zealous or deliberate concerning this aspiration. But it is not part of aspirational constitutivism that individuals be self-conscious of this aspiration or that it be part of their explicit self-conception. Indeed, for most of us most all of the time, the aspiration toward rational selfgovernance operates, as I have said, as a regulative ideal, an aspiration that largely goes unnoticed as it operates in the background of deliberation and choice. Of course, when we deliberate and choose overtly, this aspiration moves to the foreground, revealing itself whenever we consciously entertain questions about what we should choose or do.

Thus, not recognizing oneself as having this aspiration does not demonstrate one lacks it. Furthermore, the agent who denies that she aspires to rational self-governance presumptively has rational grounds for this denial-rational reflection quashes her spontaneity, impedes her unself-conscious enjoyment of various goods, invites us to see too much of our lives and circumstances as susceptible to our control, sets us up for regret when our rational choices do not pan out as we anticipated, etc. But note that this denial is not in fact a rejection of rational self-governance, but an attempt to put reason in what the denier views as its proper place. It is not the renunciation of the aspiration to rationally self-govern but an alternative rational appraisal of how reason is best put to rational use. The capacity for rational self-governance that undergirds the aspiration to rational self-governance at issue is thus austere: the capacity to respond to reasons one does or could recognize, not the capacity to live up to some more substantive norm(s) of rational choice. 
And I would therefore suggest that even the least proactive, reflective, or self-critical individuals nevertheless exhibit this aspiration in some measure. For in opting against a more rationally self-aware mode of life, these individuals tacitly take themselves to have reasons for doing so. They are staking out a position regarding the proper place of rational self-governance, and in so doing, showing themselves to be committed to the aspiration to rationally self-govern.

In the terms made familiar by Rawlsian political liberalism, the question of where reason fits within one's life is an element of one's conception of the good, i.e., of one's rational plan of life. And just as there is evidently reasonable pluralism about (for example) the place of religion or parenthood in a well-lived life, communities that respect rational agents equally can respect the diversity of ways in which individuals incorporate reason into their conceptions of the good. Equal respect for rational agency embraces maximizers and satisficers, hedonists and objectivists, type A's and type B's, planners and improvisers. Reasonable pluralism about reason itself is itself reasonable. The proper place of reason in life is therefore a question for reason, not one that questions reason. Those whose self-imposed rational requirements appear comparatively undemanding nevertheless have rational self-expectations and do not thereby reject rational self-governance. And the aspiration to be rationally effective is kinetic, but nothing mandates that it be frenetic.

Aspirational constitutivism achieves much of what the Kantian moral project seeks. The respect it recommends we owe to rational agents is rooted in a recognition of the kind of entity human beings are, namely, beings whose practical identities are intertwined with the aspiration to govern their lives on rational terms. It thus amounts to a form of respect directed at persons as such, rather than at their merits, accomplishments, etc., or at particular choices that satisfy standards of rationality. Furthermore, aspirational constitutivism can vindicate the Kantian moral norm of equal respect for rational agents. For while individuals will vary in the degree to which they aspire to rational self-governance, aspirational constitutivism does not require that individuals satisfy some threshold of rational competence in order to be entitled to respect. Again, the aspirational constitutivism predicates respect on a normative attitude common to rational agents rather than on the skillfulness with which they put their rational agency to use. 
Aspirational constitutivism also carves the boundary between agents entitled to respect and other entities in a plausible way. Instrumentally rational machines lack the aspiration toward rational agency needed to ground respect, as do many non-human animals. Human agents are thus entitled to a presumption of equal respect but not for objectionably 'speciesist' reasons. On the other hand, the overwhelming majority of human choosers, even those 'marginal cases' with depleted or incipient rational agency, give evidence of this aspiration. Still, one might worry that aspirational constitutivism casts its net too narrowly with respect to which beings are owed respect as rational agents. Are there not individuals who (intuitively) we ought to respect but for whom the aspiration to govern themselves rationally is psychologically "beyond them"? For example, might not those undergoing dementia lack this aspiration, and if so, does this entail that we ought not respect the demented?

Admittedly, some bullet biting may be in order here. A human individual who either never has the ability to exercise rational agency or the aspiration to do so effectively would not, according to aspirational constitutivism, be entitled to respect as rational agents. But as our discussion of respect in Section 1 illustrated, respect is not an attitude whose application is justifiably restricted only to rational beings. Respect is a more general stance of treating an individual or entity as having a kind of inviolable integrity. But this entails that what respect amounts to with regard to some individual or entity depends on the sort of individual or entity it is. What (say) an ancient redwood requires in the way of respect will differ from what a courtroom proceeding requires in the way of respect. ${ }^{26}$ In the case of demented or other psychologically atypical human beings, they may be entitled to a species of respect that differs from the respect to which rational agents are entitled. It is beyond the scope of this chapter to investigate what the former species of respect amounts to. Nevertheless, there may well be certain attitudes or behaviors demanded of us insofar as we aim to respect human

\footnotetext{
${ }^{26}$ I explore what respect for non-human animals, despite their lacking the essential properties of Kantian rational agency, could look like in my "A Direct Kantian Duty to Animals," Southern Journal of Philosophy 52 (2014): 338-58.
} 
individuals who do not satisfy aspirational constitutivism's conditions of respect for rational agency.

Furthermore, note that the aspiration to which I have appealed is not the aspiration to make this or that choice on grounds one can find rational. Rather, it is the aspiration to rationally govern one's life in its entirety. According to aspirational constitutivism, respecting agents' particular choices is required because the object of respect is the person qua biographical agent, and their particular choices reflect their effort to rationally self-govern their lives. This picture is compatible, however, with individuals lacking, at certain intervals or stages in life, either the capacity for rational choice or the aspiration thereunto. A precocious child may aspire to make vital choices about her life but lack the capacity to respond to reason. Conversely, a depressed person may have the capacity to respond to reason but lack the aspiration to choose, thanks to the motivational lethargy associated with their medical condition. But respect, as I conceive it, need not require that both of these be in evidence at a given moment in order for respect to nevertheless be in order. After all, the aspiration to have a rational biography overall can co-exist with intervals or stages in which that aspiration ebbs or the ability to pursue a rational biography is compromised. A rational biography is, in Sher's terms, a rationally effective one, and realizing such a biography may necessitate a kind of diachronic dexterity in the face of oscillations in one's capacity or motivation to rationally govern one's life as a whole. But so long as a person's biography contains spans in which this capacity or motivation is apparent, we may be required to respect them at times outside of those spans. So in the case of the demented individual, they may lack both the capacity and the aspiration in question. But suppose that such an individual had previously crafted a valid advance directive to be applied when her disease later renders her rationally incompetent. Ought this directive be honored, even if the demented individual opposes its being honored? Aspirational constitutivism does not justify its being honored by appealing to the authority of the earlier rational self over the later less rational self. We must instead look to which forms of treatment would best accord with her aspiration to live her life on rational terms. An advance directive is a purposeful attempt to realize that aspiration. As such, our honoring it typically validates 
that aspiration, even though the object of our respect-the demented individual's rational agency-is not present in the moment in which we are called upon to honor it.

Lastly, aspirational constitutivism is largely invulnerable to worries about systemic choice biases. Those worries have force against those views according to which respect for rational agents requires some level of proficiency in the exercise of rational agency. But aspirational constitutivism grounds respect in an essential or constitutive attitude rational agents take toward rational choice-i.e., that they aspire to govern their lives on that basis-rather than in how successful they are as rational choosers. Hence, even if we are biased in the ways outlined in the psychological literature and so are unfortunately prone to exercising our rational powers suboptimally, this does not cancel our aspiration to use those powers effectively or render it unintelligible.

\section{Exploring the Practical Implications of Aspirational Constitutivism}

Before concluding, let us get a more determinate picture of what aspirational constitutivism practically entails. If respect for rational agency is respect for the aspiration toward rational self-governance, what does this morally require of us, and how might these requirements differ from those arising from the rival understandings of equal respect for rational agency that we have considered?

Aspirational constitutivism is well-situated to do what the moral norm of equal respect for rational agency does well, namely, capture the intuitive objectionability of deception, coercion, manipulation, paternalism, etc. Such acts are objectionable, according to aspirational constitutivism, neither because they inhibit others from making rational choices nor because they fail to allow others to act on their rational capacities. These objectionable acts may well have these other features, but aspirational constitutivism will claim that they show disrespect because they do not recognize individuals' aspiration to govern their lives on rational terms. When we deceive, coerce, etc., we inhibit others from pursuing or realizing their aspiration to choose and act rationally-in 
light of their own ends, concerns, values, etc.- - typically so that they will choose and act in ways that we believe better serve our ends (or in the case of paternalism, better serve their ends). Such actions thus usurp another's aspirations and thereby treat their rational agency merely as a means. Aspirational constitutivism thus justifies the attitude toward rational agents that we earlier suggested resides at the heart of respect, namely, letting something be or honoring its integrity. Moreover, aspirational constitutivism helps explain why rational persuasion is the morally ideal mode of influencing others' attitudes. For rational persuasion enables others to pursue the aspiration to govern their lives rationally while inviting them to engage in the very activity of rational deliberation that may enable them to realize that aspiration. Rational persuasion thus engages with, rather than undermines, the property that grounds respect for rational agents, their aspiration toward rational choice.

Aspirational constitutivism has the further advantage of explaining how respect for rational agency can justify positive duties to cultivate or enhance agents' rational powers. For while some intercessions in others' rational powers will fail to defer to them in the ways respect demands, intercessions that improve the effectiveness of rational agency can be justified by appeal to agents' constitutive aspiration to govern their choices rationally over time.

Consider, for example, the contrast between nudges and what Hertwig and Grüne-Yanoff call 'boosts.'27 Nudges (for instance, using framing or ordering effects) exploit choice architecture to leverage our biases for our own presumptive benefit. Nudges will be morally worrisome on aspirational constitutivism because they arguably manipulate choice through mechanisms that fall short of standards for rational attitude formation. ${ }^{28}$ Boosts, in contrast, recognize but do not exploit biases. Rather, boosts are interventions that improve competency over time and thereby reduce bias. Compare a classic example of a nudge, placing healthier foods in a dining hall at eye level in the expectation that individuals tend to choose eye level items, with a boost, a cell phone

\footnotetext{
27 "Nudging and Boosting: Steering or Empowering Good Decision," Perspectives on Psychological Science 12 (2017): 973-86. https://doi.org/10.1177/1745691617702496

28 See Robert Noggle, “Manipulation, salience, and nudges," Bioethics 32 (2018): 164-70.
} 


\section{MICHAEL CHOLBI}

app that informs diners how many calories they have consumed to that point in a given day. The 'nudger' and the 'booster' have contrasting assumptions about the rationality of their targets: The nudger assumes her target is irremediably irrational and so justifies nudging as a way to take advantage of that irrationality for the target's benefit. The booster, on the other hand, sees the target's rationality as malleable. 'Boosting' the rationality of the target's choice does not just tend to make her immediate choices rational. It also assumes that her rational powers can be improved upon over time. Boosting thus seems morally preferable to nudging in a way that aspirational constitutivism can readily account for: A boost, unlike a nudge, respects an agent's aspiration to guide her choices on rational grounds.

These remarks are admittedly sketchy. But they suggest that in addition to the theoretical appeal of aspirational constitutivism in making sense of equal respect for rational agency, it may have practical appeal, vindicating our intuitive understanding of what such respect requires while also shedding light on harder cases where what respect requires is less obvious.

\section{Conclusion}

If aspirational constitutivism is correct, then human agents form a moral community anchored in the common endeavor of trying to govern their respective lives on rational terms. Respect among such agents does not necessitate their being paradigm practical reasoners, either in general or on particular occasions. For we can pay heed to an aspiration no less than to a capacity or to its successful exercise. In this regard, aspirational constitutivism has a more credibly Kantian pedigree than rival accounts of equal respect for rational agency. That moral and practical norms have roots in our nature as rational agents is a key Kantian claim. But it is all too easily misunderstood. Rational agency, on this Kantian picture, is presupposed not as a set of reliable causal powers we possess, but as a capacity that, because we are rational agents, we call upon ourselves to exercise in our choices and actions. In this regard, Kantian moral philosophy has an aspirational pedigree: We imperfectly (or as Kant 
would say, 'finitely' ${ }^{29}$ ) rational agents nevertheless hold ourselves and others to rational standards even in full knowledge that failures to abide by these standards may be commonplace. But the aspiration to abide by these standards, I maintain, entitles us to respect.

Aspirational constitutivism breaks with much of the recent tradition in Kantian ethics in that it does not try to accommodate deficiencies in our practical rationality by developing a non-ideal theory modeled on an ideal theory that assumes no such deficiencies. Equal respect for rational agency, I have argued, instead presupposes such deficiencies inasmuch as the host property for such respect is a shared aspiration toward practical rationality. Under aspirational constitutivism, there is no need to develop a non-ideal theory. For non-ideal circumstances are written into aspirational constitutivism at a fundamental or ground level. Equal respect for rational agency simply is respect for imperfectly rational agents, with no need to adapt moral norms of equal respect to the 'non-ideal' circumstances of imperfect rational agents. In this regard, aspirational constitutivism marries the utopian and the realistic, so as to require neither that we compromise the former when addressing the latter nor that we awkwardly attempt to address the latter as a degenerate case of the former. ${ }^{30}$ For we imperfectly rational agents are entitled to recognition respect because of our imperfections, not despite them. ${ }^{31}$

${ }^{29}$ Critique of Pure Practical Reason, Berlin Akademie Edition (1900-), 5: 123.

${ }^{30}$ John Rawls, A Theory of Justice, revised edition (Oxford: Oxford University Press, 1999).

31 A number of individuals provided valuable feedback and insights on earlier versions of this chapter, including audiences at a 2017 University of Manchester MANCEPT workshop on Moral Equality and Equal Respect, a 2018 colloquium presentation at Australian National University, the 2019 Arizona Workshop in Normative Ethics, and at the University of Saskatchewan. Particular thanks go to Arden Ali, Peter Alward, Christian Barry, Geoffrey Brennan, Brad Cokelet, David Copp, Helen Coverdale, Caleb Dewey, Robin Dillon, Giacomo Floris, Alexa Forrester, Sarah Hoffman, Pauline Kleingeld, Matthew Lindauer, Haley Mathis, Victoria McGeer, Dwayne Moore, Pierre-Francois Noppen, Emer O'Hagan, Philip Pettit, Carissa Phillips-Garrett, Costanzo Porro, Douglas Portmore, Wendy Salkin, Keshav Singh, Holly Smith, Nicholas Southwood, Ezequiel Spector, and Mark Timmons. 